\title{
DOIS ASPECTOS DO TEMA SUICÍDIO
}

NAPOLEÃO L. TEIXEIRA

Professor da Universidade Federal do Paraná: Catedrático (titular) de Medicina Legal (Faculdade de Direito); ex-Catedrático, interino, de Clínica Psiquiá. trica e de Medicina Legal (Faculdade de Medicina), da mesma Universidade.

\section{I - SUICÍDIO E SEGUROS DE VIDA II - SUICÍDIO E ACIDENTE DO TRABALHO}

É, esta, uma das mais interessantes questões da asfalologia médico-legal $\left({ }^{*}\right)$.

A difusão do seguro de vida e o aumento impressionante de suicídios, vem dando lugar a problemas psiquiátrico-legais, assaz delicados por vezes, visto ser eventualidade a requerer, com frequência, a intervenção pericial.

O autocídio - gesto desesperado derradeiro - desperta, normalmente, da parte de todos, um sentimento de piedade. Que, no entanto, deixa de existir, tão logo se põe em conflito com interesses das Companhias Seguradoras, que - cláusula-padrão, obedecida por todas - "não se responsabilizam pelo suicídio voluntário, ocorrido em qualquer época, nos têrmos do artigo 1.440 do Código Civil", considerando-se, ademais, isentas de qualquer responsabilidade pela apólice, "quando a morte do segurado for causada pelo suicídio, ainda que involuntário, durante os dois primeiros anos da data da emissão da apólice".

O artigo 1.440 de nosso Código Civil, em seu parágrafo único, conceitua, como morte voluniária "a recebida em duelo, bem como - suicídio premeditado por pessoas em seu juízo".

Vemos, assim, as Companhias de Seguros de Vida falarem, ainda,

(*) Asfalologia (do grego asfalos: seguros, e logos: ciência) - Têrmo proposto por Coppet ao Congresso Internacional de Medicina dos Seguros, em Londres, em 1935, para designar a ciência que estuda problemas ligados aos seguros. Daí derivami medicina așfalológica, asfalologia mẹ́diço-legal, etç. 
em suicídio "voluntário" e "involuntário", compreendendo àque!e como "consciente" e a este como "inconsciente". Escudadas na conceituação do primeiro, no que estatui a letra de nosso diploma civil, que o defini - vimos - como "suicídio premeditado por pessoa em seu juízo".

Carente de reforma, em muita coisa, nosso venerando Código Civil. Precisado de revisão, também nisto, à luz do que, hoje se sabe da psicopatologia do autocídio. Por arcáico; anacrônico; rançoso; old fashioned; vieux jeu; catapulia, na idade da bomba de hidrogênio; carro de bois, na éra dos teleguiados; caldeira à lenha, na hora da desintegração atômica; fraque e anquinhas, num mundo que adota roupas frescas e arejadas.

Partidário da tese psiquiátrica da autoquíria, acreditamos haver, no suicída, uma disposição psíquica anormal: a pessoa que se autoelimina, ou intenta, seriamente, fazê-lo, é anormal psíquica; anormal, ou temporariamente anormalizada. Embora episódico, passageiro, f'sgaz - um eclipse da mente existe. Não se suicida a pessoa eufrênica, normal ao seu psiquismo: a impulso inicial de auto-destruição, sucederá raciocínio lógico, conîrolador, conservador portanto, suficiente a neutralizar aquele. 'É possível", escreve MAURICE DE FLEURY, "que haja mortes voluntárias, deliberadas com malignidade, calculadas com espírito lúcido, para insu!tar o Criador na destruição da sua criatura; afïrmaram-no os românticos; moralistas nô-lo dizem, sem citar casos precisos; afirmo somente jamais haver observado algo semelhante".

- E nos casos do suicídio denominado "altruístico" ou "generoso", em que o indivíduo faz seguro e mata-se, acreditando beneficiar a família, com o premio do mesmo? Poder-se-ia, também neles, falar em anormalidade psíquica? - eis a pergunta que, arvorando um ar superior, fazem os que contraditam nossa tese.

A resposta é afirmativa: "Como en los demás grupos de suicidios, se halla indudablemente en estado de anormalidad de conciencia y su capacidad de razonar enforpece y descenłra la valoración de sus acios, sin dejarle ver la inutilidad y daño que su muerte puede proyefar sobre los seres amados" - opina ARIOSTO LICURZI. Matando-se assim, deu sua vida por pouco preço; ignorará, sem dúvida, que o dinheiro de sua apólice, como o do jogador, durará pouco. O pior virá mais tarde: seu exemplo será sempre uma espada suspensa sobre a vida dos filhos. Guardado; gravado. Um dia, em hora negra, quando se imaginarem sem horizontes, com a vida sem amanhã olharão para traz e a "coragem" do que se imolou lhes mostrará o único caminho a seguir. Lutarão uma, duas, dez, cem vezes, mas poderão acabar sucumbindo. Veremos assim, a mão do finado er- 
guendo-se, do fundo da sepultura, para dar, ela sim, a morite suicida aos que ficaram. Será este o "premio" derradeiro - bem triste premio - que seu sacrifício legará àqueles que imaginou querer ajudar...

O verdadeiro elemento etiológico é, pois, a anormalidade psíquica. Mesmo quando o ato tenha sido executado por indivíduo aparentemente em são juízo: "agiu em plena lucidez!" - afirmam, vitoriosamente, leigos, baseados em cartas, documentos, ou na maneira por que se conduziu o suicida nas horas ou dias que precederam a autoquíria.

Recorde-se, a esta altura, com ACHILLE-DELMAS, que, "la lucidité, au sens psychiatrique, peut être définie comme la conservation des faits de mémoire et le pouvoir de leur utilisation par les moyens de la dialtectique: c'est, en d'autres termes, la conservation du pouvoir de déduire et de raisonner. Notons bien que nous ne voulons pas dire ici le pouvoir de raisonner juste; on peut raisonner faux et cependant raisonner; ce n'esł̂ pas la jusłesse du jugement qui fait la lucidité, c'est seulement la conservation du raisonnement, la possibilité de raisonner, que se soit exactement ou de travers". Eferivamente, de par com loucos privados da lucidez, há os loucos lúcidos; caso do paranóico, para citar apenas um exemplo, que constrói um raciocínio perfeitamente concatenado, que só é falso por se basear numa idéia errada. Recordem-se, aqui, palavras de FREDERICI e CAPPONI, ao se referirem a loucos que "cometem crimes premeditados, revelando a calma e a tranquilidade de um espírito lúcido e sadio, iludindo, assim, aos ma:s afamados peritos profissionais.

Há, por outro lado, nos quadros da Psiquiatria, delírios raciocinantes, "loucuras lúcidas", crises emotivas, obsessões, fobias, distimias - em que o poder raciocinante se diria presente - assinala HEITOR CARRILHO, frisando a seguir: "Não se argumente, pois, com a meticulosidade, o engenho, a complicação, pois, em se tratando de suicídio - ato, por excelência, anti-natural, anti-biológico, anti-instintivo - não podem tais elementos deixar de ser patológicos, exprimindo, como exprimem, desapêgo doentio e, às vezes, impulsivo, por um bem, maior que todos, por fundamental: - o amor à vida!"

Embora aparentemente "premeditado por pessoa em seu juízo" (na linguagem do Código Civil), mesmo nestes casos deve o autocídio ser compreendido e interpretado como um ato anormal. Confessa-o mesmo o diretor da Sul América Seguros de Vida, numa palestra feita para seu "staff", subordinada ao tema "Cláusulas de incontestabilidade e de suicídio": "E muito difícil provar", diz ele, "que o suicídio foi voluntário ou consciente, pos ele é sempre resultante de um ato de desespero, de verdadeira inconsciência e, até hoje, 
nenhum psiquiatra poude asseverar que o indivíduo, no momento ae praticar tal ato, estivesse realmente em seu juízo perfeito... surge uma dúvida formidável para saber se houve, ou não, premeditação e voluniariedade do ato e se a pessoa estava em seu juízo perfeito. É uma prova quase impossível de se estabelecer" (os grifos são nossos).

"É uma prova quase impossível de se estabelecer" - fixemos bem estas palavras. Que importam em confissão de alta valia e de grande amplitude - e dela deve estar ciente causídico que tenha a seu encargo causa dessa natureza.

As companhias seguradoras só se submetem ao pagamento do seguro, nos casos de suicídio, quando tenha sido, este, "inconsciente" e, mesmo assim, se praticado depois de dois anos da data da emissão da apólice. Discordamos: partindo do conceito da anormalidade psíquica de quem se auto-elimina, somos de parecer que as companhias seguradoras deveriam ser sempre obrigadas ao pagamenio do seguro, seja qual for a época em que o suicídio ocorra. Elas, porém, de modo algum admitem seja o autocídio o fecho trágico de um rosário de vivências anormais da mente. Perdoe-se-lhes isso, de vez que não estudaram a psicopatologia da autoquíria; ou dela não foram devidamente informadas. Empacam, teimosamente, no argumento: "matou-se por sua livre vontade - e daí não saem.

Não haverá dificuldades de vulto para advogado inteligente, numa dessas causas. Mesmo porque - é importante assinalá-lo às Companhias seguradoras desagradam tais litígios que, geralmente, acabam por perder, vendo-se, no final, condenadas ao pagamento do seguro, juros e honorários, etc. Sem contar o aspecto psicológico de publicidade negativa, ponderável em questões assim, gerłlmente de grande repercussão.

Caso recente: certa senhora, em São Paulo, propôs ação contra uma Companhia seguradora, para haver, da mesma, determinada importância, correspondente ao seguro deixado por seu marido, juros e honorários. A companhia alegou, em sua defesa, o suicídio premeditado do marido. A sentença, depois de apreciar as cláusulas contratuais, e se o suicídio fora ou não premeditado, julgou a ação procedente no pedido, por existir culpa contrałual. Tendo havido apelação da Companhia para o Tribunal de Justiça do Estado de São Paulo, este negou provimento, afirmando que o suicídio resultante de loucura ou praticado por uma força irresistível, sob o impulso de uma violência física ou moral, não é um ato voluntário e livre, e 
sim produto de força maior. Salientou mais a Corte paulista que o artigo 1.440 do Código Civil, parágrafo único, considera morîe voluntária o "suicídio premeditado por pessoa em seu juízo". Donde era líciło inferir que, em face da lei, o suicídio não premeditado é morte involuntária, que não isenta o segurador. Inferposto recurso extraordinário (n. ${ }^{\circ}$ 38.063), não conheceu dele o Supremo Tribunal Federal. $O$ relator, Ministro Cândido Moła Filho, esclareceu que o parágrafo único do citado artigo 1.440 do Código Civil dizia que devia considerar-se morte voluntária a recebida em duelo, bem como o suicídio premeditado por pessoa em seu juízo. No caso, o Tribunal de São Paulo examinara a prova para concluir pela inexistência de suicídio voluntário. Não houvera, portanto, violação alguma do texto de lei. A Companhia pagou.

Tocando, portanto, à Justiça dar a palavra final, sabe dá-la e bem! Com a razão LICURZI, já citado: "Muy poco talento demonstraria el juez que aceptando la tesis del "acto voluntário" anulase la obligación del resarcimiento de una póliza de seguro".

De acordo.

\section{II}

\section{SUICÍDIO \& ACIDENTE DO TRABALHO}

Numa sessão, reaiizada pelo Colégio de Abogados de Córdoba, em honra a uma delegação de estudantes da Universidade de Chu. quisaca (Bolívia), o Professor DARDO A. RIETTI, Catedrático de Legislación Industrial y Obrera, da Universidade daquela cidade argentina, relatou interessante caso de suicídio de um operário, a seguir acidente do trabalho, que o deixou totalmente inválido, em que a indenização de modo algum poderia ser contestada.

Caso muito discutido e debatido, teve, entre outros, o mériïo de alertar a atenção dos estudiosos para este aspecto novo da autoquíria, face nova portanto, do interessante tema autocídio.

Se analisarmos a definição que o Decreto-Lei n. ${ }^{\circ}$ 7.036, de 10/11/1944, dá, entre nós, ao acideníe do trabalho, veremos que, no seu artigo $1 .^{\circ}$, considera, como tal, "todo aquele que se verifique pelo exercício do trabalho, provocando, direta ou indiretamente, lesão corporal, perturbação funcional, ou doença, que determine a morte, ou a perda total ou parcial, permanente ou temporária, da capacidade para o trabalho". E mais: considera caracterizado o acidente 
"ainda quando não seịa ele a causa única e exclusiva da morte ... bastando que, entre o evento e a morte,... haja uma relação de causa e efeito" (artigo 3. ${ }^{\circ}$ da mesma Lei).

ARIOSTO LICURZI aprecia o assunto, alinhando duas possibilidades: suicídio por medo à dor; autocídio por alterações mentais supervenientes. No primeiro caso, o indivíduo se elimina, por se considerar incapaz de suportar a dor, produzida por lesões consecutivas a um acidente do trabalho, ou por julgá-las irremediáveis e sem cura. No segundo caso, a autoquíria é o fecho doloroso de perturbações mentais, consequentes a traumatismo ou intoxicações, verificados no exercício do irabalho, ou decorrentes do ambiente em que este se realiza.

À circunstância de se raro o suicídio, como efeito de acidente do trabalho, se deve haver merecido pouca atenção da doutrina. Interessado no assunto, ocorreu-nos ouvir a palavra abalizada do ilustre professor (hoje Ministro) MOZART VICTOR RUSSOMANO; vejamos o que diz: "se, do acidente, resulta, embora indiretamente, perturbação funcional de ordem emotiva ou mental, que arraste o acidentado à morte, pelo suicídio, este suicídio é indenizável, desde que se comprove a existência, entre o acidente do trabalho e a morte, a re!ação de causalidade exigida pelo artigo $3 .^{\circ}$ da lei em vigor". Chega mesmo a admitir que a perturbação mental atue, como concausa préexisłente, determinando o suicídio, e também neste caso não haverá porque negar o pagamento da indenização respectiva, desde que a causalidade entre a morte e o acidente fique demonstrada.

Seja portador o operário-suicida, anteriormente, de psicose larvada, latente, ou não discernida por olhos leigos (há, entre nós, de 1 a 2 alienados por mil habitantes); seja o mesmo dono de personalidade psicopática (e seu número orça de 10 a 11 por cento, no Brasil).

Recordemos, aqui, com psiquiatra ilustre as "personalidades psicopáticas, fronteiriços (ciclóides e esquizóides), hiper-emotivos, neuróticos de rodo o feitio, que por aí abundam e que, muitas vezes, só pelo suicídio podem ser, retrospectivamente, diagnosticados, já que a vida dilui, mascara ou atenua, no seu polimorfismo de excitações e reações, uma infinidade de pequenos sintomas de alterações psíquica, que somente pessoas afeitas à observação da personalidade humana estariam em condições de os descobrir no meio da massa". Só depois de praticado o propricidio, é que nossa atenção é despertada para o que o realizou; verificamos, então, surpresos, que atitudes anteriores do mesmo, não levadas na devida conta, mostravam já, nítida e patente, a alteração psíquica que viria a culminar na auto-eliminação. 
Não importa: desde que o exercício do trabalho atue, direta ou indiretamente, como causa desencadeante, aí teremos configurado o acidente do trabalho - opinião nossa.

Haverá necessidade de se estabelecer o vínculo etiológico, sem o qual não se objetivará o acidente do trabalho. Embora de nem sempre fácil comprovação o nexo de causalidade entre a morte autocida e o acidente do trabalho, poderá ser isso feito através de perícia médica, ou, mais precisamente, de perícia psiquiátrica. Não se restrinja o perito ao exame do "último ało", instante em que a autoquíria se consumou. Faça mais: uma análise da conduta profissional, social e familiar anteriores do suicída, visando à descoberta de possíveis distúrbios de conduta, premonitórios de inda latente perturba. ção psiquíca. Isso, em o caso de perturbação mental pré-existente. No caso de perturbação mental superveniente (consecutiva ao acidente de trabalho), caber-lhe-á investigar até onde influiram as yivências dolorosas de ansiedade e angústia, para o gesto de desesperação derradeira.

Outro valor não tenha nossa despretenciosa contribuição a esta face pouco lembrada da Infortunística, sirva ao menos de escova ao estudo de outros, mais credenciados que nós.

Salve-se, ao menos, a intenção. O esforço de haver tentado. Mesmo porque, já dizia PASTEUR - e é sempre um consolo - nul effort est perdu.

Nota:

Aos que se interessarem por estes e outros aspectos da autoquíria, sugerimos a leitura de nosso livro sobre o tema: "O SUICíDio" (em face da Psicopatologia, da Literatura, da Filosofia e do Direito - estudo psiquiátrico, médico-legal e pro. filaxia). 